\title{
Public History in China: Is it Possible?
}

$\mathrm{I}$

n 2010, when I studied a few historic districts across China, I

concluded that authority-sharing - giving residents a chance to tell

their own stories in their own way - may seem an advanced application in China, where civic dialogues are still at peril. But such sharing points preservation efforts in a positive direction. ${ }^{1}$ The inquiry, however, did not end there: how much further have we progressed in the past three years? Is it possible to integrate public history into urban preservation in China? Is public history possible in China after all?

When Robert Kelly wrote his ground breaking 1978 article on the origin, nature and prospects of public history, he was right to focus on the idea of 'public' in training methods. ${ }^{2}$ No matter how vaguely the idea was defined at the time, public history since then has grown into an engaging intellectual discipline and active social movement in the

\footnotetext{
Public History Review

Vol 21 (2014): 20-40

ISSN: 1833-4989

C 2014 by the author(s). This is an Open Access article distributed under the terms of the Creative Commons Attribution 4.0 International (CC BY 4.0) License (https://creativecommons.org/licenses/ by/4.0/), allowing third parties to copy and redistribute the material in any medium or format and to remix, transform, and build upon the material for any purpose, even commercially, provided the original work is properly cited and states its license.
} 
United States. Articles in The Public Historian, the leading journal of the field, have explored the concept from different dimensions across different cultural contexts. Nevertheless, the core philosophy stays the same. From Carl Becker's call for 'everyman his own historian' ${ }^{3}$ to Michael Frisch's 'a shared authority', ${ }^{4}$ public history reaches out to multiple publics for a more inclusive historical interpretive power. The approach has always been critical, collaborative, entrepreneurial and, above all, self-reflective.

During my research in historic cities around the world, I found my training and experience failed to address some of the elementary issues in historic preservation: for example, whose history have we preserved, and is there anything missing from the preserved urban landscape. ${ }^{5} \mathrm{I}$ stumbled upon public history in a conversation with David Glassberg at the University of Massachusetts Amherst, where a graduate program in public history was thriving. The very idea of authority-sharing has stayed with me, though my understanding of public history has evolved in the subsequent years. I have engaged in various public history projects since 2007, as part of my training, in Massachusetts. Central to those practical experiences are a different set of values and approaches to preservation and their impact on the urban environment.

In 2009 I went to Canada for a research project on one of the most sustained urban neighborhoods in one of the most multicultural gateway cities in North America, Kensington Market in the city of Toronto. My search for historic clues acquired a firm vernacular bent: public history, especially oral history, presented an effective way to engage collective memories embedded in the historic built environment. Despite a different cultural context, the public history theories and skills that I learned in the United States found a seamless transition to Canada.

What about a radically different cultural context? In February 2013, on my way to Chongqing, China, I was again dwelling upon the question: is public history possible in China? My task this time was to teach a public history graduate seminar with historic preservation practicum at Chongqing University, one of the key national universities within the '985 Project' frame, ${ }^{6}$ and certainly the best one in Chongqing, the fourth municipality in China. In one sense, I was excited because this would be the first time I was able to ground public history in a culture where government plays a pervasive role in almost all preservation projects and decision-making remains largely top-down, no matter how the propaganda frames it. But the potential challenges came in many ways.

First, I was expecting it would meet suspicion, if not an outright pejorative response, from intellectuals in China, similarly to the way 
public history was greeted in the United States in the late 1970s. ${ }^{7}$ Most classically trained historians and professionals believe, rather stubbornly, that knowledge generated from the public does not constitute real knowledge. By the same token, public history, with its utilitarian objectives, remains a fringe intellectual exercise with little prospect of securing a footing in the traditional intellectual world. Highly prized professional aims, such as objectivity and authenticity, enshrined in established academic disciplines, seem out of place. ${ }^{8}$

The second challenge public history faces in China lies in geographic focus. In the United States, Public History programs usually favor large urban centers, for a good reason: the large employment opportunities and networks associated with those areas. So in China, the logical testing ground for public history should be metropolitan cities such as Beijing, Shanghai and Guangzhou. In Chongqing, a relatively isolated inland city of industry and commerce located in the southwest of China, on the upper reaches of Yangtze River, embracing a more cosmopolitan worldview has come rather recently, if at all. So, naturally, it poses more challenges to historical approaches that emphasize the importance of employing a more inclusive interpretive power in urban space that incorporates diverse perspectives. At stake here is not only academic authority, but also political agendas and public accessibility.

The third challenge involves the tradition of Chongqing University. Established in 1929 as a school for engineering and natural science, the University has largely stayed within this established academic culture. ${ }^{9}$ Although a new Institute for Advanced Studies in Humanities and Social Science was established to bridge this gap, disciplines in the humanities and liberal arts are still overshadowed by their engineering and science counterparts. To teach public history in an educational institution where the place of history and the liberal arts remains weak seems daunting.

Just as preservation issues in China take on different philosophic meanings, ${ }^{10}$ so too does public history. With those challenges in mind, I tried to grasp a sense of scale of the whole idea of teaching public history in China. When my plane touched down on the tarmac of Chongqing Jiangbei International Airport, my heart beat fast and emotions ran high. I could not wait to see if the vitality and creative energy of public history would find a niche here.

\section{A Reflective and Collaborative CuRRICUlum}

My first Public History course at Chongqing set out to introduce key concept and practice in the field of public history, and to encourage students to develop public history products with local historic resources. 
I wanted to get students into the field to talk to people, to see how public history could help improve historic preservation practices and, eventually, to use public history skills in whatever field they chose to practice in the future. To these ends, I structured the course in the style of seminars and practicums. The design philosophy behind it was Donald Schon's reflection-in-action, 'In an action-present - a period of time, variable with the context, during which we can still make a difference to the situation at hand - [where] our thinking serves to reshape what we are doing while we are doing it. ${ }^{11}$ Schon argues that professionals can turn to multiple publics, stakeholders or constituents to help better define who they are and make the services that they offer society more effective. This 'professional relationship' compels us, with a salutary sense of urgency, to situate our technical expertise in a meaningful social context, and to further re-define the authority issue in the context of 'reflective conversation'.

Modelled in part upon the public history program at the University of Massachusetts Amherst, ${ }^{12}$ the curriculum included five themes: philosophy and practice of historic preservation, historic interpretation at different scales, cultural landscapes, collective memory and oral history interviewing. The seminars explored key concepts and the evolution of public history in the context of historic preservation, which in China is still largely expert driven with little input from the general public. I also used my book, Kensington Market: Collective Memory, Public History, and Toronto's Urban Landscapes, as a prototype for a different kind of historic preservation practice. ${ }^{13}$

A democratic teaching style was integral to this course. Born and raised in China, I know from my own experience that traditionally the classroom is dominated by professors, with zero space for authority sharing. Students, comfortably sitting at the receiving end, are used to traditional lectures that emphasize rote learning. They are trained to respect and obey official authority, so class participation generally meets with derision. Voicing one's own opinions seems abnormal, much less to challenge the conventional wisdom. My seminars, on the contrary, invited active participation and frequent interactions.

With no prerequisite, the course was open to graduate students from all disciplines across the campus. The fifteen students who finally enrolled in class came from different yet related disciplines: they were graduate students in architecture, landscape architecture, urban and rural planning, fine arts and design. Despite this diverse educational makeup, they all came into this course with some practicum experience. ${ }^{14}$ Most of them had dabbled in historic preservation and 
some had practical experience in the field. As graduate students, they were equipped with some research skills and a reasonable level of English reading capability. The size of the class made possible an intimate climate for classroom discussions and group projects.

Instead of handing in one big paper at the end, as the students usually expect, I asked them for bi-weekly journals, as a reflective practice throughout the semester. In those regular writing exercises, students had an opportunity to hone their skills of writing in a logical and coherent manner, based on sound historic research. This is a critical capability that students in public history need to master and continually polish throughout their academic careers. It also provided some psychological space for students to reflect upon the past projects that they had done, or rather, find a new perspective into old practices.

The last critical component of the course was a six-week collaborative public history practicum. As a protean and fresh concept, public history training is more efficient if situated in specific projects that are local, immediate and relevant. For this course, students were required to analyze the preservation of major historic districts in the city, to find out hidden or under-documented histories or to offer alternative perspectives into preservation practices in those places. They worked in a three-person group, delved deeply into their chosen sites, connected the locale with a larger theme and articulated new research questions. As Noel Stowe notes, 'public history students must become actively and consistently engaged in discovering and learning how to relate the thinking of the discipline to the types of topics and situations that will emerge from their practice. Specifically, how will they deal with audience issues (especially, a contested history or conflicting voices projecting from the past)? How will they handle a wide range of professional situations (e.g., from working at historic sites to museums or historical research offices)? How will they work with professionals from their own or other disciplines, particularly the latter, who will likely introduce quite different intellectual approaches? ${ }^{215}$

With such a list of concerns, I encouraged students to deliver their final products with creativity and intellectual depth, based on rigorous scholarly research. I also asked them to practice their group presentations at least twice prior to our class conference. The hidden agenda was to hone their capacity to communicate their final products to the public with clarity and empathy. I anticipated that the last part would be awkward for most students in Chinese culture, because they simply are not used to expressing their views in the limelight. At the end, students were not obligated to write a traditional research paper. 
Instead, they handed in a reflection paper a week after the conference in which they gave their final group presentations.

\section{From the Field: Critical Reflections on URban Preservation ${ }^{16}$}

At the beginning of our class, I asked students to think deeply about the fundamental goals of historic preservation. Most of them had engaged in actual preservation projects and, not surprisingly, they were too preoccupied to reflect upon what they were doing. I posed a list of questions that included, for example, why preserve? Whose history and whose memory are kept in the preserved historic districts? Are those 'historic districts' truly preserved? These questions were aimed to help them re-think the intellectual and moral aspects of preservation. The reflective process, accumulative in nature, is also a process of constantly questioning the taken-for-granted assumptions in practice, differentiating problem setting and problem solving. In the beginning, with all of our technical expertise, have we targeted the right questions?

In China, developers and politicians work hand-in-hand against preservationists and scholars; the former decide what to build or demolish, with little or no consultation or input from the latter. Public participation in this hierarchy remains nominal at best. Students trained in relevant disciplines such as architecture and urban planning have very little political savvy to handle preservation projects in the real world. So the initial responses from my students was bewilderment: is public involvement in the preservation process really necessary? With our discussions on those issues moving along, students turned to those often ignored aspects of preservation. One student observed:

Historic districts carry a living life style, and preserving them needs to go beyond the material aspects. We need to analyze the traditional street patterns as an organic part of the traditional way of life. When 'inserting' modern architectural elements into a historic environment, we need to take those traditional patterns into consideration, or we will disrupt historic continuity. What I feel unsettled about, however, is how to accomplish this goal? How to connect modernity with history? If renovated districts truly integrate the past? Historic culture cannot be remolded, so can renovated 'historic' architecture mimicking the past truly lead us a way home? Where is this sense of home in today's preservation? My training does not answer those questions.

Another student wrote these lines from the field: 
Meandering through the historic neighborhood with a continuous grape trellis and flagstone path covered with moss, I felt an instant connection with this place. It was a rich and poetic space; lower structures lined along the path all in harmonious scales. I have been here twice, and came back with different afflatus. The tranquility is pure and emotional. I was wondering what we actually need to preserve in this kind of space. Urban texture, part of what we applaud as urban character, makes one city differ from another. It includes form and function, such as architectural scale, geometry, and space. It seems impractical to try to maintain the exact original style; those streets are, accumulated through years across seasons a direct reflection of urban spatial character and living history. What we need to preserve is ancient streets with such a pleasant scale. If we ignore those humane elements in preservation, we lose cherished opportunities to appreciate history.

One key issue which emerged from the field concerned authority: who owns history? Who owns historic space? What kind of urban and public history do we confront? One student asked:

During historic preservation, whose history are we trying to preserve, urban history, architectural history, or human history? It is different to preserve a piece of architectural wonder and a more vernacular version of historic districts, because the latter represents a living history and memory. A large number of original residents are still living in the districts, over the years across the seasons; their life style has been interwoven into the organic urban symphony. They should have a say in preserving their own space. Our field investigation shows that many have moved out of the area, with little intention of coming back. The government could care less about this. I cannot help but wonder who will continue this unique cultural tradition? Who actually owns this historic district?

Students also realized something was left out of their normal scope of professional knowledge, as the following quote suggests:

During the preliminary research phase, we have rattled through all sorts of relevant data, with a hope to get a thorough understanding of the site - it was not as smooth as expected: we 
found many contradictory descriptions from archival documents. We started to question the textual authenticity; many issues were raised yet few answers given. The materials seemed empty, repetitive, and dry. Worse, most of them were filled with political biases, and therefore misleading.

Similarly, one student noted:

When I first visited ShiBaTi (Eighteen Ladders) area, ${ }^{17}$ witnessing dilapidated stilted houses, I saw a village sandwiched in between a prosperous commercial district (Jie Fang Bei). My interviews with a few original residents in the area, however, changed my initial prejudice. They greeted us with caution, but gradually, with trust and confidence, as if we were part of their lives. This sense of being welcomed into a big family has touched me, then reshaped my professional perspective, as we seldom take humanity as part the site investigation.

The skepticism further challenges what Schon calls 'Technical Rationality' - the view of professional knowledge which has most powerfully shaped both our thinking about the professions and the institutional relations of research, education, and practice: that professional activity consists solely in instrumental problem solving made rigorous by the application of scientific theory and technique. ${ }^{18}$ The meaning of historic 'facts' changes as our understanding of history evolves.

Gradually, students started to meditate upon the fundamentals of preservation, especially the moral aspects of it. One student with an architectural design background wrote, with a tinge of cynicism: 'Historic preservation requires more 'thinking' about the past. We are often in a rush to judge, to evaluate, to criticize, yet slow to think about the educational values of the architectural heritage. When we hastily categorize the architecture, or conveniently freeze the architectural environment, or we subjectively insert our current value system, without a sense of history, so we end with a garbled history. There lies an interval between my practice and my thinking.' Connecting a sense of history with a sense of place resonates well with what David Glassberg has suggested: 'Although a sense of history is not based in physiology like a sense of smell or sight, reminders of a past even not personally experienced can evoke sensations deeply felt, such as feelings of loss, or reverie, or intense pride. Sense of history is... but a sense of locatedness 
and belonging. Sensing history, we explore fundamental questions concerning personal and group identity and our relationship to the environment. A sense of history locates us in space, with knowledge that helps us gain a sense of where we are. ${ }^{19}$

\section{THREe Men WALKING TOGETHER}

Confucius says: 'If three of us are walking together, at least one of the other two is good enough to be my teacher.' Collaboration in public history projects, however, takes more than humility and mutual respect. Elizabeth Belanger discusses teamwork skills in a recent article about a collaborative project between a small liberal arts undergraduate institution and a community social service agency in the United States. ${ }^{20}$ Teamwork forces us to face up to our own insecurities, to build up new relationships, to surrender part of one's ego and, on top of all, to work patiently and diplomatically with people who are different from us. In Chinese culture, however, individual excellence and teamwork seems strange bedfellows: conventional wisdom tells that one Chinese is a dragon; three Chinese becomes a worm. ${ }^{21}$ Teamwork, if unavoidable, takes on a different connotation: it often means parallel working at one's own capacity, then higher-ups, usually professors, make final decisions. So students rarely bother to genuinely interact with each other, and there exists little space for discussion about conflicts, contradictions and uncertainties.

For the practicum, I encouraged students to work with those from a different field, or with those whom they did not know well. Fifteen students were divided into five groups, basically out of their own choices. Relationship building took place at different levels: with academic cohorts, with informants and with the audience, and it did not come easily. One student reflected on his collaboration with two other members:

Our teamwork started with all sorts of conflicts, and many have gotten worse. Three of us come from different regions in China, with different educational backgrounds and upbringings regional cultural differences lead to different character and ways to express and deliver ourselves. Furthermore, as graduate students, we entered our graduate study with high expectations and some established, if not stubborn, thoughts and expectations, which we refused to compromise. Simple things such as finding a time to meet each other became a source of conflict. Also, three of us had to adjust our own schedules, or work at hours that we were not used to - all pose 
challenges to the fieldwork and our relationship with each other as a team.

During the long hours of discussions in our studio and field, we have learned, quite gradually, that if we are going to work this out, we have to surrender part of our egos, and deal with those rudimentary differences.

The reflection went further:

Setting back and pondering over the situation, we realized that, none of those conflicts were irresolvable and more important, once we started to put ourselves into each others' shoes, and put things in perspective, themes emerged out of 'common grounds'. It has taken a lot of patience and heart to reach this point. In retrospect, we think this somewhat painful process is simultaneously educational and worthwhile. We see those blind spots through others insights, and we gradually enjoyed the dynamics of working together for the best efficiency.

Another team acknowledged the individual differences, and consciously took advantage of them:

We compensate for each other very well: my partner is from urban and rural planning, and my background is architecture. This means we process the built environment at a different scale, but we took this difference seriously, and quite pleasantly, we enjoyed our different perspectives and analytical methodology to research issues. She collected data on urban changes and preservation policies of the site, while I dealt with architectural documents. We got along pretty well!

At our class conference, which was open to the public, in presenting their final products, students had to confront their own weakness in public speaking. ${ }^{22}$ They also needed to work with other members to deliver the message in a controlled time limit. Most of my students were not used to public speaking, as one student admitted: 'I am not good at expressing myself. I felt a little nervous when presenting in public, so I missed some important pieces of information.' Another student added time into the equation: 'as each one of us have only ten minutes, I am forced to cram a lot of information into such a short time limit. I am really nervous.' Although nervous, most students found it helpful to share their work with the public, a skill that would benefit them in their future careers. 


\section{ORAL HISTORY: ELEMENTS OF SURPRISE}

One limit of the technical approach to historic districts is that memories embedded in the material environment are often inadequately analyzed. 'By constructing and sustaining the essence of urban places,', Elisabeth Hamin and I have written, 'collective memory can help us make intellectual and personal connections with physical landscapes. ${ }^{23}$ For decades, scholars have written about memory and history, but David Glassberg is among the pioneers in linking public history and memory. He suggests, in his seminal article 'Public History and the Study of Memory', how the invention of a collective sense of place, like the invention of a public history, is part of the struggle for cultural hegemony, the product of power relations between various groups and interest. ${ }^{24}$

By making memories public, oral history provides a means for us to confront the emotional, contested and sometimes surprising elements of our present. I have gradually built this understanding from my own firsthand experience. I see a city and its architecture as 'a collective set of memory spots that enable people to create meaning to reproduce, recall, and retain their history through informal and collective actions. ${ }^{25}$ However, as a scholar, I am trained to stay objective and pursue authenticity with professional rigor. A significant portion my education has led me to this glorious goal. So the initial suspicion from my students - most of whom came into this course with a strong technical expertise, but little interaction with the subjects of, or audiences for their design and planning practices - was to be expected.$^{26}$ The emotional and sensual aspects of historic environments raise a different set of concerns in historic preservation. For example, how can we communicate private memory in a public space? How do we incorporate the 'power of shared memory ${ }^{27}$ into public understanding of the built environment? Ultimately, why does having the right version of it around us seem to matter so much?

Most students in my class had not yet used oral history as a method in fieldwork or participated in projects that involved oral history. I conducted an oral history workshop, going through basics issues and techniques. Yet experience tells me that, as many issues emerge from the field, one has to learn those skills from the field too. So when the students returned from fieldwork, we organized multiple sessions dealing with those issues. I encouraged them to brainstorm as a group first then go to the site with a general interview outline. Then we worked together to analyze the first round of interviews, adjusted research 
issues, and modified our interview questions based on the evolving themes. After making those adjustments, students went again into the field to gather further data.

From the classroom to the field, I designed the course as an open process involving ongoing conversations. In this way, students were forced to confront ambiguity, conflicts and uncertainty. Most of the situations involved politics, and they had to maneuver around those issues with patience, diplomacy and professionalism, or they could not create an effective product. It was a crash course in politics for my students. When they got into the field, they automatically turned to the spatial elements, including the building materials, architectural styles, site planning, to name but a few. It was tempting for them to take what they collected from the internet, neither processed nor questioned, plus what they saw from the field, as 'authentic' history, the avowed goal for historic preservation. Talking to actual people, anecdotally, to find out how they 'feel' about the environment seemed either unnecessary or unnatural. Not surprisingly, suspicion reigned at the initial phase of inquiry. As one student wrote:

Before we get into fieldwork, I doubted if oral history was necessary at all, along with a seemingly unbridgeable gap between theories we learned from class, and lessons we learned from field investigation. The process came not as easy as we expected. Information collected seemed scattering and misleading; we found it difficult to develop any serious research question. So we decided to take a more liberal approach, to let the interviewees' responses get us oriented.

During their first venture into the field, I got the following response from one student:

It was getting late, but I managed to interview two persons: one is a manager of a youth hostel, whose knowledge of the house remains largely bookish and superficial (this makes me think more on the meaning of 'public' history); another is a 'semioriginal resident', for lack of a better word here, who has lived in the area for 30 years, 20 years renting the same place. The apartment he owned in the last ten years was demolished though. His memory of the area falls within the last 30 years. Also, I almost had an opportunity to interview an original resident who has been around the area for more than 60 years. He was well-educated, and started to share with me his stories 
with admirable clarity and detail. Yet his wife intervened, explaining that he could not talk too much because of high blood pressure. I had to suspend the interview.

On the way back, I reflected on the interview strategies. Local residents were sensitive to demolition issues and tried to avoid discussing them, so we should hold off on them until when they felt emotionally secure to share. The interviews today went not as smoothly as expected, but surprisingly, I came back with more confidence, and even a vague sense of excitement. I am jazzed up for the next round of oral history.

This 'vague sense of excitement' epitomizes what Schon calls 'an element of surprise', ${ }^{28}$ the something that failed to meet our expectation, on which most reflection-in-action hinges. As he observes: 'When intuitive, spontaneous performance yields nothing more than the results expected for it, then we tend not to think about it. But when intuitive performance leads to surprises, pleasing and promising or unwanted, we may respond by reflection-in-action. ${ }^{29}$

Once students got oriented, they were galvanized for action. Yet more new issues emerged: 'When getting into the field, we tend to understand the physical environment, but feel awkward in talking to people: we are a little at a loss. How to talk to total strangers? How to develop rapport with them to dig out stories and memories? We have no answers to those questions. Worse, our group has not yet worked out a theme, so we feel it is difficult to navigate the interviews.' Equally compelling but hard to document is the emotional quality of the physical environment. Layers of memories have accumulated in the public space, representing a different kind of urban history: it takes place at a micro level, is deeply personal, and emotionally charged. 'It is a process full of emotion', one student wrote:

After talking to this old gentleman, I felt deeply frustrated: his memory started failing as did his body. Most of the time, he just repeated his personal experience, with little recollection of the environment. When talking to him in this crowded and dilapidated space, dwindled by the toweringly trendy Central Business District nearby, I had to doubt if historic preservation was all that necessary in the first place? Could we, professionals and scholars, just struggle for a purely authentic historic district without taking care of those living in this type of environment? Yes, we regretted the demolished buildings because part of the history was gone with their disappearance, but what about those who resided in those buildings? Their living conditions 
were in such a sharp contrast with prosperity and modernity just next door.

My students' narratives reveal a deep psychology engagement with the material environment. An inkling of uncertainty, fear, discomfort and anxiety, accompanied with a strong sense of responsibility, prevailed. This probably explains why insight distilled from oral history often enables us to get more closely in contact with the complex layers of memories behind and beyond the historic districts.

Students started to reevaluate many preservation issues, one of which concerned affordable housing. "The couple is in their $60 \mathrm{~s}$, and has lived in this area for more than three decades', one student observed:

They remembered how thrilled they were when first moving here. They were really satisfied with a 20-square-meter apartment, and the clean and friendly neighborhood. But everything has changed, unfortunately, to the worse: mice were rampant, trash scattered around. Most of the residents chose to move out, and leased their apartments at a fairly affordable price to the lowest and meanest in society. You can imagine how this has affected the neighborly relationship; the area, filled with social outcasts, becomes unsafe to walk at night. The government, in a rush for modernity, provides only too expensive housing for the original residents, so the supposedly affordable housing becomes, ironically, unaffordable. That is why this area turns to a blind spot, with an increasing crime rate and public health issues, yet is ignored by urban planners, policy makers, and government officials.

Here the students felt their role as professionals was compromised. To preserve historic districts, they often romanticize public memories and painstakingly follow rules and regulations for an objective and true history. They asked: 'Where is the humanity in all those preservation efforts? If affordable housing, built for those residents, is stripped of all humane elements, are we actually preserving for the right reason? Maybe we are playing an important role in preserving local history, but our position is embarrassingly difficult: we are sandwiched between the authority and the public.'

Only when students get into the field do they realize that the gap between historic documents and reality is wide, and their technical expertise does not bridge this gulf. At the same time, oral history offers ways to approach a culturally specific history. Students encountered 
many surprises, big and small, during fieldwork, which motivated them to immerse themselves more deeply. When talking with local residents, they confronted a living history, the impact of which is unimagined with documents. All groups reported that from the field, they found problems insufficiently addressed in textual analysis, which prompted them to reflect upon the many hidden premises of historic preservation. As one student wrote:

We have encountered many unexpected issues during interviews. We had worked out an interview outline, but not all the questions were responded to effectively. Actually, we were not expecting that they would be. Also, we were not expecting such a variety of interviewee responses: some did not want to talk too much; some needed our step-by-step guidance; still others were eloquent, eager to share their stories, so we just kept the conversations flowing.

They further compared the advantages of both documentary research and oral history:

With documents, we collected detailed data on the urban natural and built environment, which helped us tremendously in understanding the site from a macro-level; oral history, however, offers another way of reconnecting with history. We dig out many warm and fresh materials about the spirit of place, regional character, and urban soul - all, springing from one's most poetic and creative faculties, bring history back to life.

One dug deeper:

the more we talk to people, the closer we approach the historic truth: maybe this is the attraction of oral history. It recovers stories and memories, so we hear the very beat of historic evolution. It enlivens history; it makes me think deeply and critically into historic issues bounded by their material existence.

Another student had a similar response:

With oral history, we are writing another type of urban history, mainly from the grassroots. It provides not only traces and clues for personal life, emotional journey, social relationship, 
and linguistic character, but also public understanding and presentation of history. Those living and active dialogues better situate us in the historic environment; public memory as part of historical information should be integrated into architectural preservation.

\section{REFLECTION-IN-ACTION 30}

In line with the above reflections from the field, I argue that a reflective practicum, the core of a public history curriculum, works well in Chinese culture. ${ }^{31}$ Similar to business schools, public history programs need to provide their students with a pool of antecedents, exemplars and, above all, quality primary experiences; a unique theoretical framework to make sense of those experiences; and a unique repertoire of skills, qualities, evaluation systems and intellectual traditions. ${ }^{32}$ When I first introduced public history as a concept and a discipline to my colleagues in China, I sensed a tension between discipline- and professional-oriented faculties, which was not all unfamiliar. One question I often encounter is: 'Where is the theory of public history?' The logic is straightforward: if you could not articulate a list of core readings, why should the University bother to offer it? Another more implicit yet equally poignant question is: 'What is the role of our professional authority as professors?' How can we claim that those bits and pieces of 'things' generated from the 'public' are 'knowledge'? A deep sense of insecurity prevails.

The first question breaks down to where the inquiry begins, and then, how to pose the right questions. When public history started in the United States, its forebears asked similar questions. Cross-referencing the evolution of public history in other countries, ${ }^{33}$ I suggest that for public history to develop in China, instead of seeking pure and abstract 'theories', we should 'shovel for dirt' through developing local cases through practicum, then develop theories out of them. Not until we have established those cases can we advance beyond the introductory level.

Public history, collaborative and cross-disciplinary in nature, is also political. Students have learned from their first hand experience that public history has to overcome political nonexistent or unapparent barriers in western democracies. One student detailed her experience in this way:

The typical Chinese way of handling preservation issues just irritated me. It took us a lot of efforts to get the telephone number of the local office in charge of preservation and demolition issues of this district, but when we called in, nobody answered. Finally when we got through, after we told them our 
intention of locating original residents from a recent demolition project, they responded, 'wrong number!'

Another student commented more philosophically about how, for today's China, rapid economic development drives historic preservation, and how the government plays a predominant role in decision-making. This type of profit-driven preservation often comes at the price of historical truth: history and memory generated 'from below' are marginalized. For public history to survive and thrive in a nondemocratic culture, there is still a long way to go. Working with the public, we try to truly understand what historic preservation is all about. While we can easily attribute the fate of public history projects to political will, I share a positive attitude with my students. The final products they shared out of their fieldwork for this course have demonstrated that a legitimate public space exists for citizen dialogues and for authority sharing, and we should take advantage of this dynamic and thinking space.

Being political also means being culturally specific, and sometimes idiosyncratic. For the last three decades, visionary Chinese scholars have tried constantly to introduce public history as practiced in the West to local audiences. Yet they have consistently failed to go beyond the elementary step. The idea remains a vision, rather than a plan or a practice. From the early 1980s to today, public history in China has failed to yield its own original literature, to provide intellectual basis, shape public discussions and offer guidance on practical issues in the field. Why? The reason is simple: we have not yet established programs to train educators and students to develop our own skill repertoires. We have not yet made sustained efforts to develop quality case studies from the field, on which a culturally specific theoretical framework should rest. Only when this emerges can we truly change the equation.

To address the second question, I believe it is more than the professional authority of college professors that feels challenged. In the world of journalism, defensive journalists deride social media on the grounds that 'citizen journalism' undermines professional reporting. Despite this fear, 'photographs, videos and tweets from ordinary people are improving and expanding news coverage. ${ }^{34}$ Just as citizen journalism creates work for journalists who know how to curate, authenticate and analyze information from social media, ${ }^{35} \mathrm{I}$ believe that public history, instead of threatening traditional historians, offers more opportunities to bring history alive, and therefore make history more relevant to its large and diverse audience. I will not mince my words: my students seem more receptive to the theory and practice of public history 
than my colleagues. Seeing little distance between practice and theory, my students' thinking is less bounded by discipline, and more apt to find practical approaches to problems. Public history serves well in this process: its success does not depend on academically generated debates. Jack Holl writes presciently about the fundamental difference between public historians and academic historians. The problem with academicbased definitions of public history, Holl comments, is that 'they are products of an academic culture'. ${ }^{36}$

This somewhat ironically reminds me of what I discussed with my academic peers from some key universities in China in late May 2014. ${ }^{37}$ The discussions, peppered with ponderous academic jargon, seemed liberating. While we were sitting comfortably in the air-conditioned rooms arguing back and forth about different Chinese versions of the term 'public history', my students were, in over 30 degree Celsius, steamy heat, out conducting interviews in the field. All student groups came back with precious oral history data, a changed understanding of the historic districts in which they were working and, most important of all, a more persuasive understanding of what public history is all about.

A field that seems to lack a theoretical framework yet is amply practiced, needs especially strong institutional supports. Once, however, public history courses are institutionalized in the disciplinary-driven structure of Chinese universities, I am afraid the field may lose the critical edge that makes it so unique in the first place.

\section{SUggestions fOR ESTABLISHINg PUBLIC HIStORY PROgRAMS IN CHINA}

To establish public history programs in China, a well-structured approach needs to be taken to get students in touch with the core scholarship of the field, and with a range of public work environments as well. To break this down, I have come up with the following three suggestions.

First, public history can actually foster cross-disciplinary collaborations. Comprehensive universities, such as Chongqing University, should take advantage all of its campus resources, encouraging students to take courses from different departments based on the tracks they choose to take on. As systematic methodological training is still unavailable in most graduate schools in China, the public history seminar model in which students genuinely engage with the public, works at a minimal level as a method course or a module.

Second, local historical study and experience should be integrated in the core history curriculum. Urban preservation projects in China, for example, are grounded in a local setting, so collecting sources and data 
must take place at a local level. By focusing on local pasts and taking advantage of local resources, students can be encouraged to practice oral history to bring the past alive for local residents.

Third, a selection of skill-oriented classes specifically designed for Chinese culture should be part of a public history program. As a new discipline, public history programs need specially trained educators. ${ }^{38}$ Faculties should engage with people already practicing ways of relating to the past, participate in the process of sharing and establish a professional relationship with the public and other 'stakeholders'.

The vitality and creative energy of public history has made its way into China. Shortly after finishing up this course, one doctoral student in my class decided to focus his dissertation on five major ethnic minority cultural districts in China, with public history as the key methodology. A few master students have, in their follow-up correspondence, shared with me their interest in using public history in future projects. Most of them noted that, given more time, they would improve their interviewing skills, and thus the quality of their oral history data.

On my flight back to the United States, I received notes and email from students, saying the idea of public history has greatly expanded their intellectual horizon and motivated them to think deeply, critically and historically about preservation issues. It is gratifying to read through those letters. The semester seemed a crash course for me as well. My students in Chongqing University were truly inspirational. They have taught me that we do not have to surrender different interpretations of historic districts to notions of technical expertise in the service of political power. In a nut shell, public history is taking shape in China.

\section{Acknowledgements}

This project is co-funded by National Social Science of China (Project Number: 14XSS007) and Interdisciplinary Research Projects in Humanities and Social Sciences, Chongqing University (Project number: CDJKXB14008). The author would like to thank Marla Miller and David Glassberg for commenting on the early draft of this article. Jannelle Warren-Findley, Paul Ashton and Paula Hamilton have contributed to this work in various ways.

\section{ENDNOTES}

${ }^{1} \mathrm{Na} \mathrm{Li}$, 'Preserving Urban Landscapes as Public History: The Chinese Context', The Public Historian, vol 32, no 4, 2010, pp60.

${ }^{2}$ Robert Kelly, 'Public History: Its Origins, Nature, and Prospects', The Public Historian, vol 1, 1978, pp16-28.

${ }^{3}$ Carl Becker, 'Everyman His Own Historian', The American Historical Review, vol 37, no 2, 1932, pp221. 
${ }^{4}$ Michael H. Frisch, A Shared Authority: Essays on the Craft and Meaning of Oral and Public History, Suny Series in Oral and Public History, State University of New York Press, Albany, 1990.

${ }^{5} \mathrm{Na}$ Li and Elisabeth M. Hamin, 'Preservation', in Rachel Weber and Randall Crane (eds), Oxford Handbook of Urban Planning, Oxford University Press, Oxford, 2012, pp183-187.

${ }^{6}$ The 985 Project, started in 1998, is an effort to build world-class research universities by Chinese government, which provides policy and financial supports for innovative systems, team-building, research flat-forms and centers, and international collaborations. About 30 universities across China are selected into this highly reputed project.

${ }^{7}$ This expectation was proved right. On 17 April 2013, I gave a lecture on public history and urban landscapes at Chongqing University. The idea of 'a shared authority in urban space' met overwhelming suspicions. The disciplinary base of public history was questioned by my academic peers at Chognqing University. About details about my talk, please refer to http: / / ias.cqu.edu.cn/GYY / chinese / detail.aspx?NewsId=6331.

${ }^{8}$ David Glassberg cautioned in 2013, ‘[Difficulty] winning over "objective" academic historians at your university, is to be expected and really echoes what goes on here (not every university in the US is as friendly to public history as UMass Amherst).' He also noted the difficulty of determining 'the place of knowledge generated from the ground up (from the people) in a society that still seems very hierarchical and authoritarian.' Correspondence with David Glassberg 28 April 282013.

${ }^{9}$ The University has a high-ranking architecture and planning program in the country.

${ }^{10} \mathrm{Na} \mathrm{Li}$, 'Preserving Urban Landscapes as Public History: The Chinese Context', The Public Historian, vol 32, no 4, 2010, pp52.

${ }^{11}$ Donald A. Schön, The Reflective Practitioner: How Professionals Think in Action, Basic Books, New York, 1983, pp26.

${ }^{12}$ Marla Miller, Director of Public History Program at the University of Massachusetts Amherst, has been extraordinarily helpful in offering guidance on my curriculum design.

${ }^{13} \mathrm{Na}$ Li, Kensington Market: Collective Memory, Public History, and Toronto's Urban Landscape, University of Toronto Press, Toronto, forthcoming 2015.

${ }^{14}$ Studios are requirement for obtaining BA in those fields.

${ }^{15}$ Noel J. Stowe, 'Developing a Public History Curriculum Beyond the 1980s: Challenges and Foresight', The Public Historian, vol 9, no 3, 1987, pp52.

${ }^{16}$ All quotes are taken from students' journals, reflection papers, assignments and conversations. Students consented to the use of those materials under the condition of anonymity.

${ }^{17}$ Legend says that ShiBaTi means eighteen stone ladders leading to the only well in this region.

${ }^{18}$ Schön, The Reflective Practitioner, p23.

${ }^{19}$ David Glassberg, Sense of History: The Place of the Past in American Life, University of Massachusetts Press, Amherst, 2001, pp7.

${ }^{20}$ Elizabeth Belanger, 'Public History and Liberal Learning: Making the Case for the Undergraduate Practicum Experience', The Public Historian, vol 34, no 4, 2012, pp30-51.

${ }^{21}$ Dragon, an imaginative animal in Chinese culture, here symbolizes and outstanding individual who brings glory to the family and the community. In contrast, worm means someone at the lowest social ladder. This saying indicates how Chinese lacks quality and spirit to work together.

${ }^{22}$ We posted our class conference via social media such as we-chat and a poster. A few people who are engaged in the Old Chonqing and Memory project turned out and raised many questions.

${ }^{23} \mathrm{Li}$ and Hamin, 'Preservation', p186. 
${ }^{24}$ David Glassberg, 'Public History and the Study of Memory', The Public Historian, vol 18, no 2, 1996, pp19.

${ }^{25} \mathrm{Li}$ and Hamin, 'Preservation', p187.

${ }^{26}$ This has something to do with the strong emphasis on physical aspects of urban design and planning in China.

${ }^{27}$ Frisch, A Shared Authority, p88.

${ }^{28}$ Donald A. Schön, Educating the Reflective Practitioner: Toward a New Design for Teaching and Learning in the Professions, Jossey-Bass, San Francisco, 1987, p27.

${ }^{29}$ Schön, The Reflective Practitioner, p56.

${ }^{30}$ Stowe references Donald Schon, Nicolas Maxwell and Ernest Lynton to conceptualize public history as a reflective practice. This part extends his argument. See Noel J. Stowe, 'Public History Curriculum: Illustrating Reflective Practice', The Public Historian, vol 28, no 1, 2006, pp39-65.

${ }^{31}$ I have then taught the similar course in the subsequent two semesters, and the practical reflections from students reinforce this argument.

${ }^{32}$ Schön, Educating the Reflective Practitioner, p312.

${ }^{33}$ Many articles published in The Public Historian touched upon public history practices outside the United States but mainly in the English speaking world. For example, vol 32, August 2010, on professional practices of public history in Britain and vol 21, February 2009 on Public History in Canada. I was fortunate to work as International Affiliate at Centre for Oral History and Digital Storytelling,

Concordia University, and as Visiting Research Fellow at Australian Centre for Public History, University of Technology Sydney, to learn how public history is practiced and taught in Canada and Australia. Conversations with Steven High, Paul Ashton and Paula Hamilton have greatly helped me think through establishing public history in China.

${ }^{34}$ 'Citizen Journalism: Foreign Correspondents', The Economist, 1 June 2013 p61.

${ }^{35}$ ibid.

${ }^{36}$ Jack M. Holl, 'Cultures in Conflict: An Argument against "Common Ground" between Practicing Professional Historians and Academics', The Public Historian, vol 30, no 2, 2008, pp48.

${ }^{37}$ On 24 May 2013, a nation-wide seminar on public history - its concepts, theories, practices, and development in China - took place at The Institute for Advanced Studies in Humanities and Social Sciences, Chongqing University. Participants included thirteen scholars who have engaged in public history from major universities across China. This is the first conference that is dedicated to public history in China.

${ }^{38}$ The first Public History Faculty Training Program took place in Shanghai from 1830 July 2014. See my forthcoming article (in Chinese): Na Li, 'Public History in a Cross-Cultural Perspective: The First Public History Faculty Training Program in China', World History Review, vol 1, 2015. 